\section{4 㜿腕力と惩垂・投力}

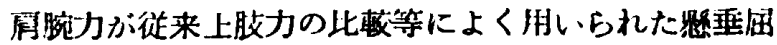
塆回数や投力にも机划な保があることはすでに報告した

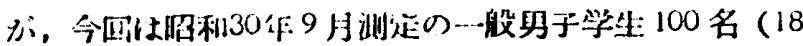

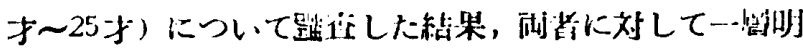

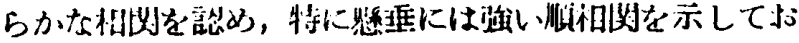

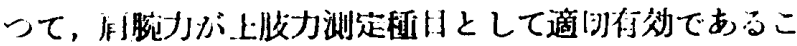
とボかかる。

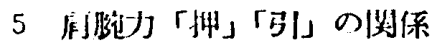

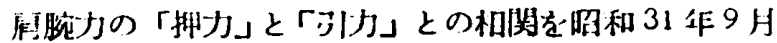
测定の…般男子学生 300 名 (18才〜25才) および女子等

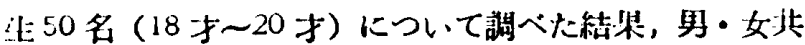

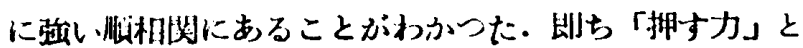

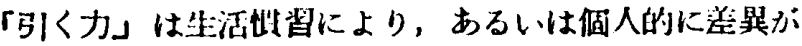
占のても，一般にその独さは相伴うむのであると将えて 上ホカ3。

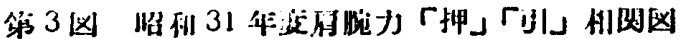

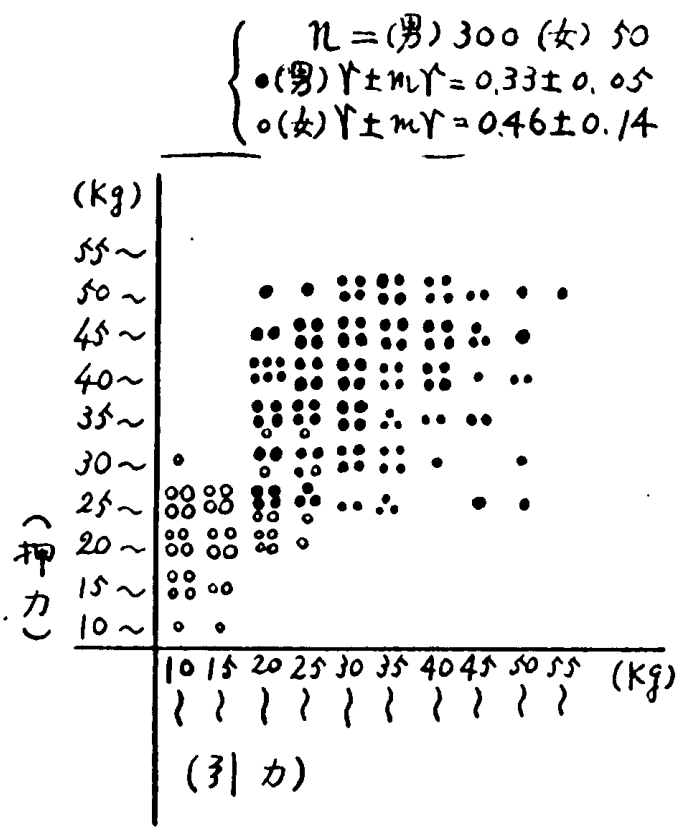

6 むすび

二回にわたつて報告した如く，本学々生 3750 名（昭

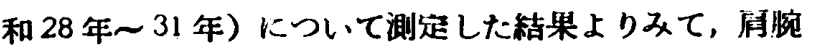

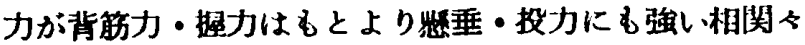

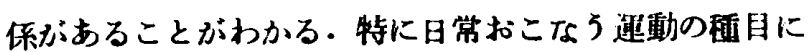
上つて強弱の盖があることは，体力指摽としての価伯去 一粠明らかにするるので，本学においては今後も学生の 体力測定項目の一つとして笑施する考えである。

\section{体言の成果に閶する一考腺}

就都学芸大学

○商山司朗，向井 義，木下 利子

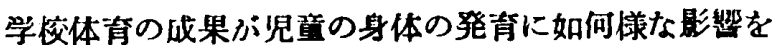

及ばすかを究めようとして，京都市内に执いてて過去数尔 間にわたつて学校体青ないし学校体青笛理に全校あげて

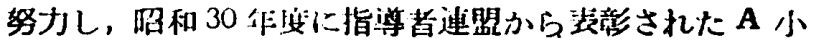

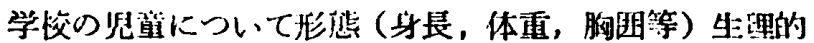

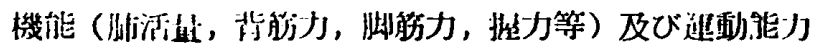
(50m 走，汒㘦跳，ボール投等) 等について测造を行 いっこの秥果をA 校とはば同等な環筧下にあつて普通に 体有け理を行つているB校の测定值と比較検討した。

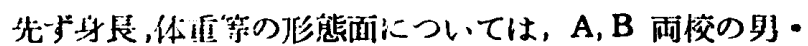

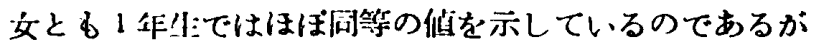

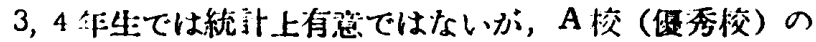

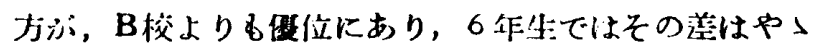
小さくなる倾向を示した。份現㑐の 5 ，6作生の者の学校

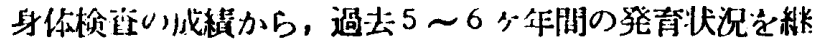

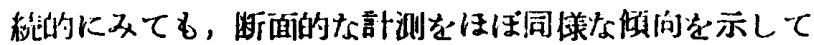
いた。

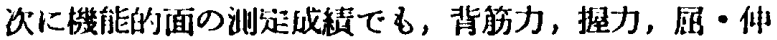

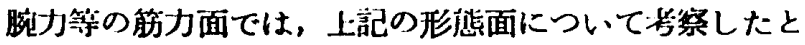
同殹な発青頓向をたどり，A校の発育度が俱れていた (有空でない).しかし刖活业ではこのよろな一定の㑯问

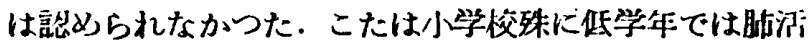
埴の正しい洲起は目難で，筷差が大ぎいためではないか と思われる。

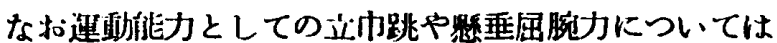
男女とるA校のうゔその発達速度が侵れていたが，ンフ トボール投の成維では各学作とす逆にB校が侵仙にあつ た。これは A，B 酎校は家这瑵境は闰校な地区であつた

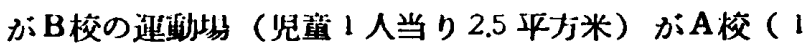

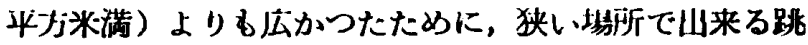

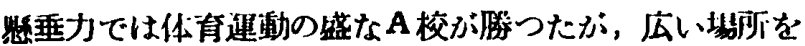
必要とする投挍ではB校が練酱の機会が多いためではな いかと考えられる。

䢋に雨校の児童の体育活動についてて関心をみ上5と して，3 年生以上の児望に䆓問秖法によつて，今日の笪 休みに，又令日の放課後に先ず何をしたいかを寻ねたと ころ，B校では漠然と遊びたい，連動したい，或いはン フトボールをしたい、答える他に家に牌えりたい，或い は境此や唱歌等と答える者も的 $30 \%$ \%かか，A 校では 鉄梅，跳箱，巾跳，かけつこ等の基砆的な運動稫日や， ドッチボール，ソフトボール等，目的的にスポーツ（遊

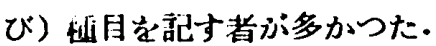

身体の発有は先天的，後天的な諸条件に夻右されるる のであつて，以上の资料から体育の効果を諭ずるのは齿 だ危険であるが，学校体青に関心の梁い、A 校の罗董が， 身体的面に抋いて一般にB校上り传位にあつたのは，学 校の体青管理方公理的で児望の体青活動に対する関心刃゚ 
高く，又これを笑践していることが大きな要因と考えら れる。 。

ハスケツトホール邆手の侉格について

$$
\begin{aligned}
& \text { 照取大䇣 } \\
& \text { 山本方非 }
\end{aligned}
$$

(1) 跡えが要

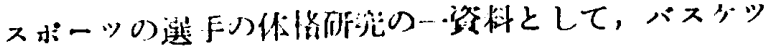

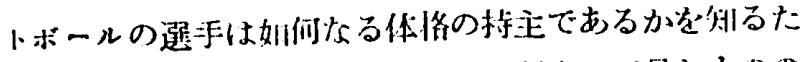

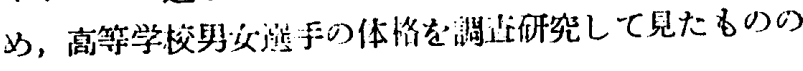
報笘でむる。

(2) 刘象亚に一j法

刘象とした選手は，服和31年8月7日〜11 日の间鳥 取沁の会塄じ行われた，全日本男女高校 パスケットボール選手椎大会に参加した 经国各都道拊紧の代泰チームであり，そ の人員は，男子 55 チー 725 人，女子 53 チーム668 人計 1393 人である.

此の内, 罗于 647 人，女子 647 人望集

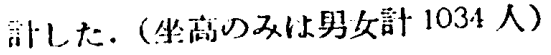

瓷料は7 月小面各チームに最近のもの を求めたその報告によつた。

(3) 成 鈢

集計成綃は次の沮りである・第】表は

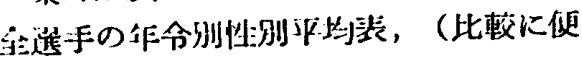
利のため昭和 30 年活の身体綡計を亚記 した。

(4) 溚察

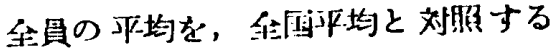
と，哥女北身長は $3.6 \mathrm{~cm} \sim 7.6 \mathrm{~cm}$, 体值 は $3.6 \mathrm{~kg} \sim 7.7 \mathrm{~kg}$ ，胸卧は $2.2 \mathrm{~cm} \sim 4.0 \mathrm{~cm}$ 大である。坐高のみは，男子17 年，女 子15才，18 才は相小である.（第1浸参 照)

名位㯰列の全国将均との比較は，身長

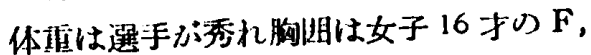
18 才のGが䅌㸝る。坐海は各年のG（男 子）各年の FG (女子) が我つている。

的位㯰则の比恔は，15 才男子の F の 坐荡，15 才女子 $\mathrm{G}$ の身長，16 才女子 $\mathrm{G}$

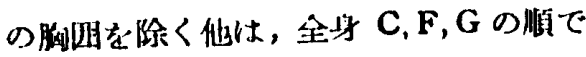
ある.（第 2 表式结）

最大最小别に見ると，Cに大なる者が 居り最小なる者はGに配膡されいる顾们 がある。(第 3 裴)

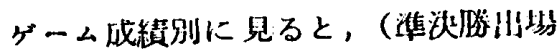
チームを集棓して見た)。がーム成績の 艮好なるチームの体格の他の選手上り䃆

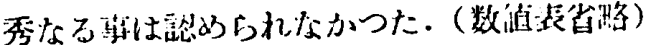

(5) むとおきき

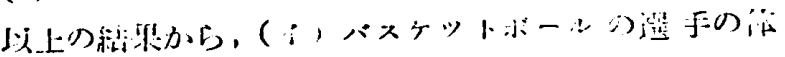

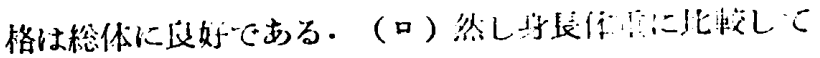

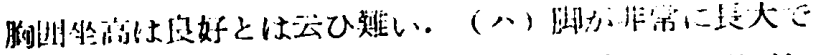

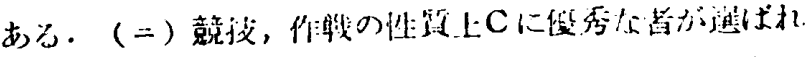

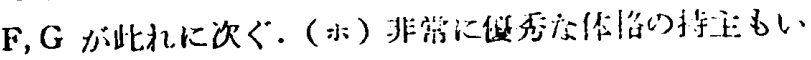

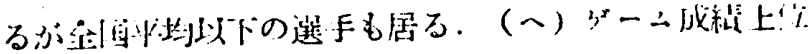

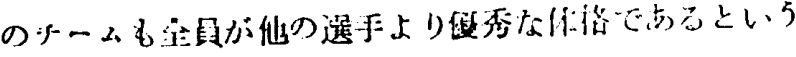

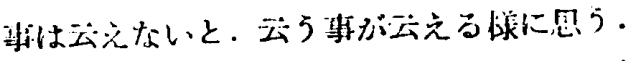

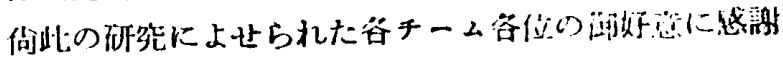

\begin{tabular}{|c|c|c|c|c|c|c|c|c|c|c|c|}
\hline \multirow[b]{2}{*}{ 件令 } & \multirow[b]{2}{*}{ 位畕 } & \multicolumn{5}{|c|}{ 男 } & \multicolumn{5}{|c|}{ 女 } \\
\hline & & $N$ & 乐辰 & 传重 & 枯 1 田 & 坐息 & $N$ & $y$ & 体国 & 肉更 & $\underline{1}$ \\
\hline 15 & \begin{tabular}{|l|}
$C$ \\
$F$ \\
$G$ \\
\end{tabular} & $\begin{array}{l}10 \\
422 \\
42 \\
4\end{array}$ & \begin{tabular}{|l|}
172.9 \\
166.7 \\
163.7 \\
\end{tabular} & $\begin{array}{l}60.3 \\
56.1 \\
55.6\end{array}$ & $\begin{array}{l}84.8 \\
82.8 \\
823\end{array}$ & \begin{tabular}{|l|}
$89.3(9)$ \\
$87.2(31)$ \\
$87.3(32)$ \\
\end{tabular} & \begin{tabular}{|l|}
21 \\
50 \\
60 \\
\end{tabular} & \begin{tabular}{|l|}
161.7 \\
156.0 \\
159.7 \\
\end{tabular} & $\begin{array}{l}51.7 \\
50.7 \\
48.0\end{array}$ & $\begin{array}{l}81.6 \\
78.7 \\
78.4\end{array}$ & $\begin{array}{l}85.4(19) \\
62.5(43) \\
822(44) \\
\end{array}$ \\
\hline 16 & $\begin{array}{l}C \\
F \\
G\end{array}$ & \begin{tabular}{|c|}
44 \\
90 \\
100 \\
\end{tabular} & $\begin{array}{l}175.0 \\
1696 \\
164.8 \\
\end{array}$ & $\begin{array}{l}64.0 \\
58.6 \\
56.0 \\
\end{array}$ & $\begin{array}{l}83.9 \\
84.7 \\
82.4 \\
\end{array}$ & \begin{tabular}{|l|}
$92.1(22)$ \\
$88.9(86)$ \\
$86.6(71)$ \\
\end{tabular} & \begin{tabular}{|l|}
37 \\
100 \\
89 \\
\end{tabular} & \begin{tabular}{|l|}
101.5 \\
156.7 \\
153.3 \\
\end{tabular} & $\begin{array}{l}54.5 \\
50.8 \\
50.6 \\
\end{array}$ & $\begin{array}{l}80.9 \\
79.5 \\
80.4 \\
\end{array}$ & $\begin{array}{l}86.4(27) \\
83.4(74) \\
834(54)\end{array}$ \\
\hline 17 & $\begin{array}{l} \\
F \\
G\end{array}$ & \begin{tabular}{|c|}
40 \\
107 \\
84 \\
\end{tabular} & \begin{tabular}{|l|}
175.5 \\
169.3 \\
165.2 \\
\end{tabular} & $\begin{array}{l}65.3 \\
59.8 \\
58.0 \\
\end{array}$ & $\begin{array}{l}88.1 \\
85.5 \\
85.3 \\
\end{array}$ & \begin{tabular}{|l|}
$92.2(34)$ \\
$89.5(92)$ \\
$86.8(76)$ \\
\end{tabular} & $\begin{array}{l}43 \\
93 \\
75 \\
\end{array}$ & \begin{tabular}{|l|}
163.8 \\
157.4 \\
154.7 \\
\end{tabular} & \begin{tabular}{|l|}
55.9 \\
53.1 \\
50.9 \\
\end{tabular} & $\begin{array}{l}925 \\
82.0 \\
80.7 \\
\end{array}$ & $\begin{array}{l}865(35) \\
84.2(74) \\
83.0(58)\end{array}$ \\
\hline 18 & $\begin{array}{l}c \\
F \\
G \\
\end{array}$ & $\begin{array}{l}17 \\
410 \\
38 \\
\end{array}$ & \begin{tabular}{|l|}
178.1 \\
171.4 \\
166.4 \\
\end{tabular} & $\begin{array}{l}69.3 \\
62.5 \\
57.9 \\
\end{array}$ & $\begin{array}{l}90.0 \\
86.9 \\
847 \\
\end{array}$ & \begin{tabular}{|l|}
$91.1(19)$ \\
$90.7(33)$ \\
$080(39)$
\end{tabular} & \begin{tabular}{|l|}
13 \\
29 \\
36 \\
\end{tabular} & \begin{tabular}{l|}
163.1 \\
157.9 \\
154.9 \\
\end{tabular} & \begin{tabular}{|l|}
58.1 \\
53.9 \\
52.4 \\
\end{tabular} & $\begin{array}{l}83.1 \\
81.5 \\
80.6 \\
\end{array}$ & \begin{tabular}{|l}
$869(10)$ \\
$83.9(23)$ \\
$82.9(0)$ \\
\end{tabular} \\
\hline 19 & $\begin{array}{l}c \\
F \\
G\end{array}$ & 1 & $\begin{array}{l}186.0 \\
175.0 \\
171.0\end{array}$ & \begin{tabular}{|l|}
73.0 \\
66.1 \\
62.0 \\
\end{tabular} & $\begin{array}{l}91.0 \\
90.0 \\
90.0\end{array}$ & \begin{tabular}{|c|}
04.0 \\
96.4
\end{tabular} & & 157.0 & 56.0 & 84.0 & \\
\hline
\end{tabular}

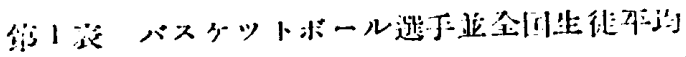

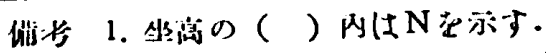

2. B.Pはバメケットボールの選子文示す。

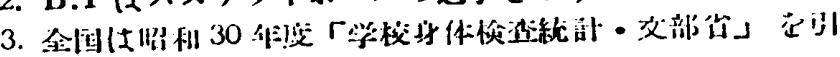
川主.

\begin{tabular}{|c|c|c|c|c|c|c|c|c|c|c|}
\hline & & $\mathbf{N}$ & $\cdot$ 長 $_{\text {cm }}$ & S.D & 体 直 & $\$ 0$ & 胸 $\mathrm{II}_{\mathrm{cm}}$ & S.D & 坐 高 & $\$ 0$ \\
\hline & & $94 \mathrm{~N}$ & $\begin{array}{l}166.0 \\
158.5\end{array}$ & $\begin{array}{l}4.6 \\
6.7 \\
\end{array}$ & $\begin{array}{l}56.5 \\
48.8\end{array}$ & 6.3. & $\begin{array}{l}82.8 \\
78.8 \\
\end{array}$ & $\begin{array}{l}3.8 \\
4.7\end{array}$ & $\begin{array}{l}875(72) \\
86.0\end{array}$ & $\begin{array}{l}3.3 \\
4.1\end{array}$ \\
\hline & B. & $13 \mid$ & 158.6 & $\begin{array}{l}5.6 \\
4.9\end{array}$ & $\begin{array}{l}49.6 \\
46.8\end{array}$ & $\begin{array}{l}50 \\
50 \\
85\end{array}$ & $\begin{array}{l}79.0 \\
77.9\end{array}$ & $\begin{array}{l}3.9 \\
3.4\end{array}$ & $\begin{array}{l}82.9(103) \\
83.7\end{array}$ & $\begin{array}{l}3.6 \\
2.9 \\
\end{array}$ \\
\hline & 要 & 224 & $\begin{array}{r}168.3 \\
161.6\end{array}$ & $\begin{array}{l}5.9 . \\
6.0\end{array}$ & $\begin{array}{l}58.2 \\
52.2\end{array}$ & 6.00 & $\begin{array}{l}83.5 \\
8 i .3\end{array}$ & $\begin{array}{l}7.2 \\
4.5\end{array}$ & $\begin{array}{l}88.4(179) \\
87.9\end{array}$ & $\begin{array}{l}41 \\
3.7\end{array}$ \\
\hline 16 & 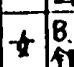 & 226 & $\begin{array}{l}156.2 \\
152.6\end{array}$ & $\begin{array}{l}4.2 \\
4.9\end{array}$ & $\begin{array}{l}51.4 \\
48.7\end{array}$ & $\begin{array}{l}4.8 \\
5.5 \\
5.5\end{array}$ & $\begin{array}{l}80.0 \\
79.6\end{array}$ & $\begin{array}{l}3.4 \\
4.4\end{array}$ & $\begin{array}{l}85.8(1155) \\
84.2\end{array}$ & $\begin{array}{l}3.1 \\
2.8\end{array}$ \\
\hline & 男 & & $\begin{array}{r}168.9 \\
163.4\end{array}$ & $\begin{array}{l}5.5 \\
5.6\end{array}$ & $\begin{array}{r}60.0 \\
54.5\end{array}$ & $\begin{array}{l}5.3 \\
5.8 \\
\end{array}$ & $\begin{array}{r}85.9 \\
83.0 \\
\end{array}$ & $\begin{array}{l}3.8 \\
4.8 \\
\end{array}$ & $\begin{array}{l}88.9(202) \\
89.0\end{array}$ & $\begin{array}{l}4.3 \\
3.4\end{array}$ \\
\hline 17 & $女$ 女列 & 211 & $\begin{array}{r}157.8 \\
153.2\end{array}$ & $\begin{array}{l}8.7 \\
48.8\end{array}$ & $\begin{array}{l}52.9 \\
49.8\end{array}$ & $\begin{array}{l}4.9 \\
5.7\end{array}$ & $\begin{array}{l}81.7 \\
80.5\end{array}$ & $\begin{array}{l}3.6 \\
4.4\end{array}$ & & $\sqrt{3.1}$ \\
\hline & 娚 & 95 & 170.6 & $\begin{array}{l}60 \\
55\end{array}$ & $\begin{array}{l}61.8 \\
55.1\end{array}$ & {$\left[\begin{array}{l}6.0 \\
5.6\end{array}\right.$} & $\begin{array}{l}86.6 \\
83.7\end{array}$ & $\begin{array}{l}5.0 \\
4.3\end{array}$ & $\begin{array}{l}89.6(911) \\
88.8^{-1}\end{array}$ & $\begin{array}{l}3.9 \\
3.3\end{array}$ \\
\hline 18 & & 78 & $\begin{array}{l}157.4 \\
152.8\end{array}$ & $\begin{array}{l}4.9 \\
4.9\end{array}$ & $\begin{array}{l}53.9 \\
50.3 \\
\end{array}$ & \begin{tabular}{|l|}
4.7 \\
5.3 \\
\end{tabular} & $\begin{array}{r}81.3 \\
81.2 \\
\end{array}$ & $\begin{array}{l}3.6 \\
4.4\end{array}$ & & $\begin{array}{l}3.3 \\
2.8\end{array}$ \\
\hline & $\bar{s}$ & 3 & 177.3 & 6.3 & $\begin{array}{l}67.0 \\
55.4\end{array}$ & $\begin{array}{l}4.4 \\
5.4\end{array}$ & 90.3 & $\begin{array}{l}4.7 \\
4.3 \\
\end{array}$ & $\begin{array}{l}100.212 \\
88.8\end{array}$ & 3.4 \\
\hline & 5 & & $\begin{array}{l}157.0 \\
152.5\end{array}$ & 4.9 & $\begin{array}{l}56.0 \\
50.2\end{array}$ & 5.3 & $\begin{array}{l}840 \\
81.4\end{array}$ & 4.8 & 84.2 & 1.20 \\
\hline
\end{tabular}

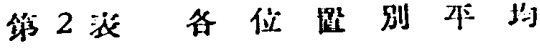

㑣涪 $\mathrm{C}$ はセンター，Fはフォワード，Gはガード

(149) 